\title{
Participatory Landscape Design Detroit: A Tool for Environmental Education and Action
}

M'LIS BARTLETT ${ }^{1 *}$

Volume 2, Fall 2014

http://dx.doi.org/10.3998/mjs.12333712.0002.008

${ }^{1}$ School of Natural Resources \& Environment, University of Michigan,

Ann Arbor, Ml 48109

*Corresponding author: M'Lis Bartlett, mlis@ umich.edu

\section{ABSTRACT}

While landscape architects use participatory landscape design to engage communities in creating new outdoor spaces, environmental educators and activists across the country are engaging young people in similar gardening projects to improve the urban environment. These hands-on experiences can build students' connection to and understanding of their environment, thereby supporting future environmental stewardship. This paper describes the evolution of a community-based participatory research collaboration that used a participatory landscape design program called The Ugliest School Yard to explore how the participatory design process might be used to enhance environmental literacy. The pilot project revealed that the participatory process may do more than increase knowledge. It may provide a platform for collective action for landscape regeneration and stewardship.

Our schools are like jails, there are bars on windows and security guards through the hall. And we have no place to play. These oft-repeated comments came from a series of neighborhood meetings held by East Michigan Environmental Action (EMEAC). These discussions came as no surprise to the staff at EMEAC, a Detroit-based nonprofit that addresses environmental justice concerns throughout southeast Michigan. EMEAC staff had seen firsthand how in some Detroit neighborhoods, dilapidated streetscapes and overgrown parks have changed the quality and safety of 
outdoor open spaces for youth. Inspired by the Canadian Biodiversity Institute's Ugliest School Yard Contest, EMEAC's staff decided to pilot a program entitled the Ugliest School Yard, Detroit in order to address their communities' requests for a more supportive school environment.

Early in my doctoral program, I had been exploring parallels between the participatory landscape design process and best practices in environmental education. When EMEAC asked me to be the lead designer for Ugliest School Yard, it seemed like a useful context in which to explore my research interests. For two years, EMEAC staff and I piloted this participatory landscape design program to help students learn about and steward new schoolyard green spaces. Via a community based participatory research (CBPR) process, I brought theoretical discourse regarding participatory design and environmental education to bear on the evolution of EMEAC's Ugliest School Yard program. CPBR engages community members and researchers in a shared process of research and action in which the researcher addresses an issue of interest to the community, and community capacity is strengthened via engagement in various parts of the research process (Israel et al. 2005). Through extensive conversations regarding our different skill sets and needs as an environmental justice organization and as a doctoral student, we made several key changes to EMEAC's initial program. First, we would work collaboratively with students to co-create new outdoor spaces — not make gardens for them; and second, we would work with $8-10^{\text {th }}$ graders rather than elementary school youth. These changes enabled us to explore how greening a school landscape might improve student learning outcomes in terms of environmental knowledge and stewardship. This paper describes the piloting of a participatory landscape design program that laid the groundwork for a subsequent study of minority youth and collective action for landscape regeneration and stewardship.

\section{Participatory Design and Teens}

Participatory landscape design (PLD) is one of many participatory design processes that engage stakeholders and designers in a shared creative process that enhances outcomes for end-users. Participatory design employs a variety of techniques including stakeholder meetings, workshops, and model making in which designers learn from user experts (Yamauchi 2012). In the participatory design process, user, or local experts share experiences or needs related to product design that might not occur to the professional designer. 
Specifically, participatory landscape design is a shared process of place-making that draws on professional and local knowledge (Hester 2006). At its best PLD enhances local ecological systems and illuminates historic human relationships to place, by engaging participants in a collaborative process of environmental stewardship (Hayden, 1995). In large-scale landscape improvement projects, PLD has been shown to elicit a sense of ownership that promotes the sustainability of place (Crewe and Forsyth 2003). It is a challenging process requiring deft facilitation that balances the needs of stakeholders with various levels of expertise and power (Juarez and Brown 2008).

In youth environments, landscape designers have utilized PLD to engage youth and families in the construction of playgrounds and skate parks. This type of participatory process, while not always identified as such, is also being used by environmental educators and classroom teachers working with students to create butterfly habitats, raised vegetable beds, and outdoor classrooms. Enthusiastic anecdotal accounts of these programs describe their influence on youth and the local environment. Yet there are few critical examinations of the PLD process in environmental justice contexts, nor is it clear how the collaborative design process might benefit the young people who participate. When I described the potential of the PLD process to EMEAC staff, they were excited as it aligned closely with their mission to empower youth to learn about and act to change their communities.

We chose to work with young teens for several reasons. EMEAC was aware of extensive academic and professional discourse that asserts the need for elementaryschool-aged children to engage with the natural world for health, social, and cognitive development (Francis 1995; Louv 2005; Taylor et al. 1998). We discussed how the availability of safe green space promotes an early relationship with nature and influences future environmental concern and civic action (Bixler and Floyd 1997; Wooley et al. 2008). Less is understood about teenagers' relationships to nature. A recent national study argues that while teens may know about environmental problems, they do not feel confident in their ability to address these issues (McBeth 2010). Other studies suggest that teens, focused on other social needs, may need to take a break from nature (Kaplan and Kaplan 2002). Even less is known about minority teens' relationships to nature, especially those living in urban contexts. For these teens, daily contact with landscapes and communities stressed by social and environmental inequities may increase a sense of powerlessness that mitigates their interest and engagement in environmentally responsible behavior (Strife 2008). Additionally, a lack of experience with nature and the way outdoor education experiences are framed may leave minority teens feeling disconnected from nature (Bixler 
and Floyd 1997). Upon further discussion, EMEAC staff noted that in their experience, funding for elementary school gardens was often readily available, and that the focus on teens would fill a hole in their programming and respond to needs expressed by older students.

\section{Ugliest School Yard, Detroit}

These frank discussions of on-the-ground experience and academic discourse helped frame our pilot gardens. To start the process, EMEAC staff sponsored the Ugliest School Yard Contest through their community networks in Southwest Detroit and Brightmore. The competition required schools to demonstrate a need for schoolyard improvement and an interest in the collaborative process, as well as the capacity and commitment to maintain the site post installation. The competing schools served students from low socio-economic backgrounds and of African American descent. Two schools were public and two were charter; all served neighborhood youth. Each was distinct in its educational programming, with varied school-wide themes including technology, Afro-centric learning, and community service.

Due to teacher turnover and other administrative challenges, we often did not know what grade or subject our collaborating teachers would be teaching. Therefore, the 16-week program was designed to work in a variety subject areas-English, science, and art—at grade levels $8-10$. Topics were loosely divided into two content units, urban ecology and cultural connections to landscape, and were facilitated in 40- to 50-minute periods once a week. The project included hands-on workshops, opportunities for student-based inquiry, focus groups for student sharing, and time for expert sharing. Field trips and PowerPoint presentations showed students a series of landscape design alternatives.

Best practices in environmental education describe how effective environmental education encourages students to care for and learn about the environment, analyze environmental issues, and participate in environmental actions (NAAEE 2013; UNESCO 1977). Theorists Hungerford and Volk (1990) have proposed that environmentally responsible civic behavior evolves from a combination of variables that parallel these educational goals. These variables include sensitivity or care towards the environment, in-depth knowledge of an issue, and the knowledge or the skills needed to act. The PLD process provided a scaffold for building a connection to place, knowledge about place, and application of knowledge through design. Throughout the program, students kept journals of drawings, poetry and 
interviews. The journals provided a way to express previous experience and apply new competencies. For example, following a lesson on urban agriculture, they were asked to draw and describe how they might enhance their schoolyard for pollinators.

Following the content units, students worked in small groups to create 3-D models of their ideal school landscapes. Their models became the basis for a functional schoolyard garden design. This design was reviewed by students, staff, and administrators. I made adjustments according to their feedback. Participatory processes can suffer from an imbalance of power, and this is especially true of youthcentered programs (Hart 2008; Woolner et al. 2007). Through periodic reflection sessions with EMEAC staff and teachers, we attempted to balance student voices, school staff needs, and designer expertise. This was not a perfect solution, but it did ensure that this issue stayed at the forefront of our decision making process. We wanted the design to be driven by student ideas, but garden sustainability also required adult care and stewardship, and we needed to honor staff input as well as the students' ideas.

All garden designs were driven by the students' ideas and expressed needs. The students' designs drew on themes of human health, habitat restoration, and their desire for safe social spaces for learning and play. Depending on school needs, funding, and staffing, each new school garden was built over the summer or through the following school year-sometimes with the help of EMEAC staff and the researcher, sometimes without. Students participated in the construction of all school gardens. One construction project was woven into a summer school program; in another, students were paid through a summer youth employment program. Projects included a new school entryway, several courtyard gardens, and a garden of meditation.

\section{Next Steps}

Following each project, students were asked to fill out a short evaluation describing their experience of the program. Their answers indicated that they had gained new environmental knowledge ("Birds eat insects") and that they had gained some confidence in changing their environment, ("I learned you could take ugly to pretty"). Given the curriculum, this was not unexpected. What was unpredicted was their expressed enthusiasm for working together to improve their school landscapes ("I liked putting my ideas together with a group and seeing how it turned out"). Their 
comments indicate a desire to work collaboratively to make positive changes in their local environment.

Hungerford and Volk (1990) have proposed that effective environmental education should give students a sense of connection to the environment, in-depth knowledge about environmental issues, and a skill set for action. These variables, along with a personal sense of responsibility and self-efficacy, can support environmental literacy and participation in environmental actions (Hollweg et al. 2011). Others describe the influence of a caring mentor on future environmental action (Chawla 2007). Like much environmental education discourse, this work examines the impact of experience on individual behavior. In addition, students' feedback reflected the influence of the participatory design process on collective action.

Environmental education discourse has focused on the relationship between individual knowledge and behavior change as a basis for future involvement in environmental stewardship. As the EMEAC staff and I discussed what we had learned from the students' reflections on the program, we were inspired to look at the issue of environmental action a little differently. In a declining economy, environmental justice communities need more than ecological knowledge to concurrently address pressing social and environmental concerns, we need to understand more about how people-particularly youth—act collectively for environmental change. Understanding more about collective action may provide insight into community resilience and just sustainability through environmental restoration. The participatory landscape design process in school setting creates a platform for examining how re-building a schoolyard may build teens' individual and collective efficaciousness for addressing environmental concerns in their communities.

\section{References:}

Bixler, Robert D., and Myron F. Floyd. 1997. "Nature is Scary, Disgusting, and Uncomfortable." Environment and Behavior 29 (4): 443-467.

Chawla, Louise. 2007. "Childhood Experiences Associated with Care for the Natural World: A Theoretical Framework for Empirical Results." Children Youth and Environments 17 (4): 131158.

Crewe, Katherine, and Ann Forsyth. 2003. "LandSCAPES: A Typology of Approaches to Landscape Architecture.” Landscape Journal 22 (1): 37-53. doi:10.3368/lj.22.1.37.

Francis, Mark. 1995. "Childhood's Garden: Memory and Meaning of Gardens." Children's Environment 12 (2): 1-16.

Hart, Roger. 2008. "Stepping Back from 'The Ladder': Reflections on a Model of Participatory 
Work with Children." In Participation and Learning, edited by Alan Reid, Bjarne Bruun Jensen, Jutta Nikel, and Venka Simovska, 19-31. Springer: Netherlands.

Hayden, Dolores. 1995. The Power of Place: Urban Landscapes as Public History. Cambridge, MA: MIT Press.

Hester, Randolph T. 2006. Ecological Democracy. Cambridge, MA: MIT Press.

Hollweg, Katherine S., Jason Taylor, Rodger W. Bybee, Thomas J. Marcinkowiski, William C. McBeth, and Pablo Zoido. 2011. Developing a Framework for Assessing Environmental Literacy: Executive Summary. North American Association of Environmental Educators. Accessed January 23, 2014. http://www.naaee.net/framework.

Hungerford, Harold R., and Trudi L. Volk. 1990. "Changing Learner Behavior through Environmental Education." Journal of Environmental Education 21 (3): 8-21.

Israel, Barbara A., Eugenia Eng, Amy J. Schulz, and Edith A. Parker, eds. 2005. Introduction to Methods in Community Based Participatory Research for Health. San Francisco: Josey-Bass.

Juarez, Jeffrey A., and Kyle D. Brown. 2008. "Extracting or Empowering? A Critique of Participatory Methods for Marginalized Populations.” Landscape Journal 27 (2):190-204.

Kaplan, Rachel, and Stephan Kaplan. 2002. "Adolescents and the Natural Environment: A Time Out?" In Children and the Environment:Theoretical, Conceptual, and Empirical Investigations, edited by P. H. Kahn and S. R. Kellert, 227-257. Cambridge, MA: MIT Press.

Louv, Richard. 2005. Last Child in the Woods: Saving Our Children From Nature-Deficit Disorder. Chapel Hill: Algonquin Books.

McBeth, William. 2010. "The National Environmental Literacy Project: A Baseline Study of Middle Grade Students in the United States." The Journal of Environmental Education 41 (1): $55-67$.

NAAEE (North American Association of Environmental Educators). 2013. What Is Environmental Education? Accessed December 20, 2013. http://www.naaee.net/what-is-ee.

Strife, Susan. 2008. "Growing up in an Environmental Justice Context: Children's Environmental Concerns.” Environmental Justice 1 (4): 217-224. doi:10.1089/env.2008.0520.

Taylor, Ann F., Angela Wiley, Frances E. Kuo, and William C. Sullivan. 1998. "Growing Up in the Inner City: Green Spaces as Places to Grow.” Environment and Behavior 30 (1): 3-27.

UNESCO. 1977. Intergovernmental Conference on Environmental Education, edited by UNESCO with UNEP. Tbilisi: UNESCO.

Wooley, Michael, Andrew Grogan-Kaylor, Megan E. Glister, Rebecca A. Karb, Larry M. Gant, Thomas M. Reischl, and Katherine Alaimo. 2008. "Neighborhood Social Capital, Poor Physical Conditions, and School Achievement." Children and Schools 30 (3): 133-145.

Woolner, Pam, Elaine Hall, Kate Wall, and David Dennison. 2007. "Getting Together To Improve the School Environment: User Consultation, Participatory Design and Student Voice.” Improving Schools 10 (3): 233-248.

Yamauchi, Yutaka. 2012. "Participatory Design." In Field Informatics, edited by Toru Ishida, 123138. New York, Heidelberg, and Berlin: Springer. 